\title{
Development of a Precipitation-Strengthened Matrix for Non-quenchable Aluminum Metal Matrix Composites
}

\author{
NHON Q. VO, ${ }^{1,5}$ JIM SORENSEN, ${ }^{2}$ ERIC M. KLIER, ${ }^{3}$ \\ AMIRREZA SANATY-ZADEH ${ }^{1}$ DAVAADORJ BAYANSAN, ${ }^{1}$ \\ DAVID N. SEIDMAN, ${ }^{1,4}$ and DAVID C. DUNAND ${ }^{1,4}$ \\ 1.-NanoAl LLC, Skokie, IL 60077, USA. 2.-CPS Technologies, Norton, MA 02766, USA. \\ 3.-Army Research Laboratory, APG, Adelphi, MD 21005, USA. 4.-Department of \\ Materials Science and Engineering, Northwestern University, Evanston, IL 60208, USA. \\ 5.—e-mail: nvo@nanoal.com
}

\begin{abstract}
Recent developments in metal matrix composite-encapsulated ceramic armor show promise in lightweight armor technology. The system contains ceramic tiles, such as alumina, sandwiched between unreinforced aluminum or aluminum metal matrix composite (Al-MMC), which has a better toughness compared to the ceramic tiles. The sandwich structures should not be quenched during the fabrication, as the large mismatch in the coefficients of thermal expansion between the ceramic tiles and the unreinforced aluminum or Al-MMC creates internal stresses high enough to fracture the ceramic tiles. However, slow cooling of most commercial alloys creates large precipitates making solute unavailable for the formation of fine precipitates during aging. Here, we develop a non-quenched, high-strength metal matrix utilizing dilute Al-Sc-Zr alloys. We demonstrate that the dilute Al-0.09 Sc-0.045 Zr at.\% alloy and the same alloy containing $0-4$ vol.\% alumina short fibers do not result in precipitation upon slow cooling from a high temperature, and can thereafter be aged to increase their strength. They exhibit a moderate strength, but improved ductility and toughness as compared to common armor aluminum alloys, such as AA5083-H131, making them attractive as armor materials and hybrid armor systems.
\end{abstract}

\section{INTRODUCTION}

For kinetic energy (KE) armors, current advanced lightweight armor designs rely upon hybridized systems incorporating ceramic materials, such as alumina and silicon carbide tiles, to provide the essential stopping power for a variety of important threats. Polymeric composite and metallic "backface" materials, in turn, are used to provide stiff support of the ceramics and damage tolerance to satisfy different multi-hit requirements. A successful backface material must have high stiffness and strength, in addition to substantial ductility/damage tolerance upon impact by a projectile. Various monolithic wrought metals and polymeric composites have been used with ceramics in multi-layer designs. Such armor systems can, however, be difficult and expensive to manufacture, and performance is often compromised by bonding and interfacial issues. Ultimately, cost is the determining factor for the selection of KE armors.
Efforts to improve backface performance have sought to exploit metal matrix composites (MMCs) and periodic core (PC) materials/structures. These materials offer significant increases in specific stiffness and specific strength (MMCs) and plate bending stiffness (PCs), which are factors that have been previously shown to enhance the stopping power of the ceramic. Efforts to reduce the cost of hybridized armor systems have explored encapsulation processing, which is essential to the effective utilization of ceramics in the most demanding passive armor concepts because it provides substantial confinement and even residual compressive stresses within the ceramic. There are many approaches to encapsulation processing, and perhaps the most costeffective method is via liquid-metal encapsulation. A typical fabricating process consists of two stages. First, the stacked layers of reinforcement tiles are positioned within a closed casting mold. Second, the liquid metal is infiltrated into the casting mold under pressure, thereby encapsulating the stacked 
layers of tiles. The casting mold is typically in the form of a near-net shape of the final armor product. An example of this new ceramic encapsulated armor system is CPS HybridTech Armor ${ }^{\circledR}$, having aluminum or aluminum metal matrix composite (AlMMC) as the encapsulating matrix and individual alumina, silicon carbide or boron carbide tiles as ceramic layers. ${ }^{1}$ A further benefit of this approach is that different types of reinforcement materials, including ceramic particulates, fibers and tiles, can be utilized in the hybrid ceramic/metal/MMC system.

Liquid-metal encapsulation processing has, however, many challenges. To successfully fabricate a liquid-metal/MMC-encapsulated hybridized armor, the residual stresses due to processing and to cooling from the processing temperature with very large coefficient of thermal expansion (CTE), mismatches between ceramic and metal must be managed to create the necessary confinement of the ceramic tile, without overstressing or cracking them. The overall strength and damage tolerance of the hybrid structure is dependent upon the joint and bond-line/interface properties, which is determined by the chemistry of the encapsulating metal and the kinetics of the process. Incorporation of reinforcement particles, fibers, etc. can further complicate the story as they introduce their own alloy chemistry restrictions.

Ultimately, one of the biggest challenges in any hybridized material system is maximizing the properties, particularly strength and toughness in the case of armor, of the encapsulating metal or MMC given all the previously noted constraints, such as CTE mismatch and deleterious chemical reactions between the metal matrix and ceramic tiles and/or the reinforcement phase for MMC. To further complicate matters, the hybridized systems currently envisioned are very large $(\sim 1 \mathrm{~m}$ in length and width), with thick cross-sections $(5-10 \mathrm{~cm})$. During processing, including solidification, relatively slow cooling rates result from the large thermal mass, which are required to relax internal stresses resulting from CTE mismatch to prevent damage to the encapsulated ceramic. In most commercial aluminum alloys, cooling from casting to ambient temperatures creates large precipitates, making, however, solute unavailable for the fine precipitates formed on subsequent aging, which provide strength to the alloy. The CTE between the ceramic and encapsulating metal also precludes the typical sequence of solutionizing, quenching and subsequent precipitation aging.

Several commercial aluminum alloys exist with both high strength and toughness (defined here as the plastic energy during tensile testing; i.e., the area under the tensile stress-strain curves), which include AA5083-H131 (with an ultimate tensile strength (UTS) of $310 \mathrm{MPa}$ and a toughness of $36 \mathrm{MPa} \mathrm{m}^{-3}$ ) and AA6061-T6 (with an UTS of $310 \mathrm{MPa}$ and a toughness of $35 \mathrm{MPa} \mathrm{m}^{-3}$ ).
However, most of these alloys contain magnesium, which is highly reactive with alumina and forms an aluminum magnesium spinel, $\mathrm{MgAl}_{2} \mathrm{O}_{4}$, on the surfaces and within the alumina tiles or alumina fibers in the MMC. ${ }^{2}$ This degrades the alumina's strength and the bonding between the Al-MMC and alumina layer. ${ }^{2}$ The $\mathrm{Al}-\mathrm{Mg}$-O phase equilibria suggests that the $\mathrm{MgAl}_{2} \mathrm{O}_{4}$ spinel is in equilibrium with both $\mathrm{Al}_{2} \mathrm{O}_{3}$ and $\mathrm{Mg}$ concentration up to $6-7 \%$. $^{2}$ Among Al alloys, only commercially-pure $99.7 \% \mathrm{Al}$ and $\mathrm{Al}-2 \mathrm{Cu}$ (wt.\%) alloy appear to have a negligible reactivity with alumina for the long times at elevated temperature required for the processing of hybrid materials. ${ }^{2}$ Both of these alloys have, however, relatively low yield strengths (14 MPa for $99.7 \mathrm{Al}$ and $69 \mathrm{MPa}$ for $\mathrm{Al}-2 \mathrm{Cu}){ }^{3}$ Several heattreatable $\mathrm{Al}$ alloys without $\mathrm{Mg}$ exist, but the required slow-cooling from solidification (e.g., unquenched) prevents their utilization, as solutes precipitate as coarse phases during slow cooling, thereby reducing their strength upon subsequent aging. Al-MMCs (with finer micron-size reinforcement than the tiles in the form of fibers or particulates) can also be utilized in the hybrid materials system as the encapsulating matrix. They suffer, however, from having very low ductility, thereby imparting low toughness, especially for high-volume fractions of the ceramic reinforcement. ${ }^{4}$

In this article, we present a newly-developed, dilute $\mathrm{Al}$-alloy, which can be used unreinforced or as the matrix of a short-fiber Al-MMC with a low volume fraction of ceramic reinforcement that: (1) are heat-treatable after slow-cooling from solidification (i.e. do not require quenching); (2) have relatively high yield and tensile strengths; (3) have a relatively high elongation; and (4) have, therefore, high toughness compared to the currently utilized Al-alloys and Al-MMCs in hybridized materials systems. The new Al-alloy contains small concentrations of scandium and zirconium and the corresponding MMC has $\sim 4$ vol.\% of Saffil $^{5}$ short alumina fibers ( $>96$ vol. $\% \mathrm{Al}_{2} \mathrm{O}_{3}$ ). The dilute $\mathrm{Al}$ $\mathrm{Sc}-\mathrm{Zr}$ alloy, cast by an infiltration process, slow cooled and aged, has a yield strength of $128 \mathrm{MPa}$ and an elongation of $31 \%$, resulting in a toughness of $\sim 41 \mathrm{MJ} \mathrm{m}^{-3}$. The Al-Sc-Zr/4\% Saffil composite has a yield strength of $127 \mathrm{MPa}$ and an elongation of $10 \%$, resulting in a toughness of $\sim 18 \mathrm{MJ} \mathrm{m}^{-3}$. The toughnesses of these two materials are about 8and 3-fold higher than the best performing $\mathrm{Al}-2 \mathrm{Cu} /$ $15 \%$ Saffil composite, which is currently utilized in the hybridized materials system.* The nonquenched, heat-treatable, high-toughness Al-alloy and Al-MMC have potentially novel applications in improved hybrid materials systems.

\footnotetext{
*Data provided by CPS Technologies Inc.
} 


\section{EXPERIMENTAL PROCEDURES}

Two ternary Al-0.09 Sc-0.045 Zr (Alloy 1) and Al$0.06 \mathrm{Sc}-0.03 \mathrm{Zr}$ (Alloy 2) at.\% alloys (at.\% is used hereafter unless otherwise noted) were cast from 99.99\% pure $\mathrm{Al}$, as well as $\mathrm{Al}-2 \mathrm{Sc}$ and $\mathrm{Al}-1.6 \mathrm{Zr}$ wt.\% master alloys. The melting was performed in alumina crucibles in an air furnace at $800^{\circ} \mathrm{C}$. Al-Sc and $\mathrm{Al}-\mathrm{Zr}$ master alloys were preheated to $640^{\circ} \mathrm{C}$ before being added to the $\mathrm{Al}$ melt to accelerate their dissolution during melting. The alloyed melt was maintained in air for $30 \mathrm{~min}$ at $800^{\circ} \mathrm{C}$ to insure dissolution of the $\mathrm{Zr}$ and Sc, vigorously stirred, and then cast into a graphite mold and subsequently icewater quenched. The two ingots were then rapidly heated to $\sim 660^{\circ} \mathrm{C}$, and maintained in the solid state at $\sim 660^{\circ} \mathrm{C}$ for about $10 \mathrm{~min}$ (close to their liquidus temperatures). They were then cooled to room temperature at three different cooling rates: (1) water quench $\left(\sim 5000^{\circ} \mathrm{C} / \mathrm{min}\right)$; (2) fast oven-cooled with the furnace door opened $\left(\sim 8^{\circ} \mathrm{C} / \mathrm{min}\right)$; and (3) slow oven-cooled with the furnace door closed $\left(\sim 4^{\circ} \mathrm{C} / \mathrm{min}\right)$. The cooling rate, which is the rate at the start of the cooling process, is approximate for the water-quenching case, while it was measured directly using the furnace's thermocouple for the fast and slow oven-cooling processes. The temperature-time history for the three cooling processes is plotted in Fig. 1. Chemical analyses of all as-cast

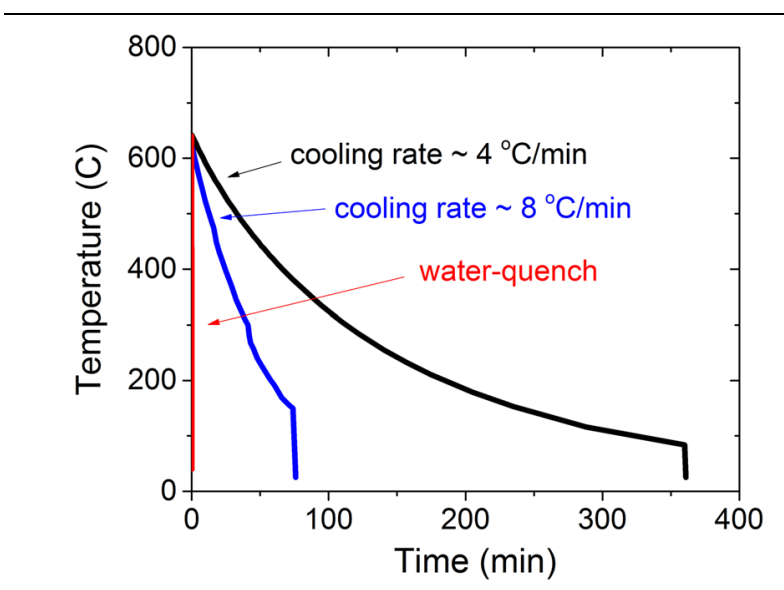

Fig. 1. Temperature versus time during cooling from $660^{\circ} \mathrm{C}$ to room temperature by: water quenching $\left(\sim 5000^{\circ} \mathrm{C} / \mathrm{min}\right)$; faster oven cooling with the furnace door open $\left(8^{\circ} \mathrm{C} / \mathrm{min}\right)$; and slower oven-cooling with the furnace door closed $\left(4^{\circ} \mathrm{C} / \mathrm{min}\right)$. alloys, which were sampled at different positions in the ingot, was performed by DCP-OES (direct coupled plasma-optical emission spectroscopy) at ATI WahChang (Oregon).

The Al-Sc-Zr/Saffil composite plates $(80 \times 25 \times$ $3 \mathrm{~mm}^{3}$ ) were produced via pressure infiltration using Saffil fibers in form of both paper and preform. Saffil consists of high-purity crystalline alumina fibers, stabilized by a small amount of silica $(<4 \mathrm{vol} . \%)$. It is comprised of uniform fibers with diameters ranging from $2 \mu \mathrm{m}$ to $4 \mu \mathrm{m}$. Saffil paper binds the short millimeter-long fibers by a combination of organic and inorganic binders in a paperlike structure, was utilized to fabricate the Al-Sc-Zr/ 4 vol.\% Saffil composite. A Saffil preform was utilized to fabricate the Al-Sc-Zr/15 vol.\% Saffil composite. The Saffil preform consists of milled Saffil fibers with lengths on the order of hundreds of micrometers, which are mixed with organic and preceramic binders and formed into boards by vacuum forming on a screen. The mixture is then fired to remove organic binder and bond the fibers at fiber contact points into a porous board with a fiber volume fraction of $15 \%$. The pressure infiltration casting procedure has been described in detail elsewhere. ${ }^{6}$ The Saffil short fibers were oriented randomly in the plate's plane. The Al-Sc-Zr alloy, utilized for the infiltration casting, was prepared as described above (Alloy 1, Table I).

Vickers microhardness measurements were performed with a Shimadzu HMV-G 21DT microhardness tester utilizing an applied load of $100 \mathrm{~g}$ for $5 \mathrm{~s}$ on samples polished to a $0.05-\mu \mathrm{m}$ surface finish. Different applied times did not alter the measurement values. More than ten indentations, in different grains, were made for each specimen to improve the statistics. The average diagonal dimension of an indentation is $50-80 \mu \mathrm{m}$. The average spacing between short fibers is $\sim 12 \mu \mathrm{m}$ in $\mathrm{Al}-\mathrm{Sc}-\mathrm{Zr} / 4$ vol.\% Saffil and $\sim 4 \mu \mathrm{m}$ in the Al-Sc-Zr/15 vol.\% Saffil composite samples. Electrical conductivity measurements were performed on the mounted samples utilizing a Sigmatest 2.069 eddy current instrument (Foerster Instruments, Pittsburgh, PA, USA). Five measurements were performed at frequencies of $120 \mathrm{kHz}, 240 \mathrm{kHz}, 480 \mathrm{kHz}$, and $960 \mathrm{kHz}$ for each specimen. The electrical conductivity is the average of 20 measurements for each specimen. An Hitachi TM3000 scanning electron microscope (SEM)

Table I. Nominal composition of Alloy 1 and Alloy 2; chemical analysis by direct current plasma optical emission spectrometry $(D C P$-OES $)$ is also included

\begin{tabular}{|c|c|c|c|c|}
\hline & \multicolumn{2}{|c|}{ Nominal composition, at.\% (wt.\%) } & \multicolumn{2}{|c|}{ DCP-AES, at.\%, (wt.\%) } \\
\hline & Sc & $\mathbf{Z r}$ & Sc & $\mathbf{Z r}$ \\
\hline Alloy 1 & $0.090(0.15)$ & $0.045(0.15)$ & $0.084(0.14)$ & $0.045(0.15)$ \\
\hline Alloy 2 & $0.060(0.10)$ & $0.030(0.10)$ & $0.053(0.09)$ & $0.033(0.11)$ \\
\hline
\end{tabular}


equipped with a detector, manufactured by Bruker Nano, for energy-dispersive x-ray spectroscopy (EDS) measurements, were utilized for detecting large primary precipitates. Tensile testing was performed with specimens having the flat dogbone-shape with a gauge length of $12 \mathrm{~mm}$, a width of $5 \mathrm{~mm}$ and a thickness of $3 \mathrm{~mm}$, machined by electrical discharge machining without final grinding and polishing. The tensile samples were machined from cast coupons having uniform thickness of $3 \mathrm{~mm}$. Thus, the surface of the flat dog-boneshaped specimens was not machined, but rather the original cast surface was used, which already had reasonably good surface finish for tensile testing. The tensile tester (Instron Model 4206) was utilized. The tensile strain rate was $3.3 \times 10^{-3} \mathrm{~s}^{-1}$.

\section{RESULTS}

\section{Aging Treatment Optimization for the Alu- minum Matrix}

Electrical conductivity and microhardness measurements are displayed in Fig. 2a and b for both alloys as a function of cooling rate. For Alloy 1, water quenching and fast oven cooling $\left(\sim 8^{\circ} \mathrm{C} / \mathrm{min}\right)$ results in the same electrical conductivity $(\sim 31.2$ MS $\mathrm{m}^{-1}$ ) and microhardness (200 $\mathrm{MPa}$ ) values, which also matches the values for an $\alpha$-Al matrix,, 8 suggesting that this cooling rate range is sufficient to maintain $\mathrm{Sc}$ and $\mathrm{Zr}$ in a supersaturated solid solution. Slow oven cooling $\left(\sim 4^{\circ} \mathrm{C} / \mathrm{min}\right)$ results in higher electrical conductivity $\left(\sim 32.0 \mathrm{MS} \mathrm{m}^{-1}\right)$ and much higher microhardness (360 MPa), indicating that $\mathrm{Al}_{3}(\mathrm{Sc}, \mathrm{Zr})$ precipitation has occurred. For Alloy 2 , at all cooling rates, similar electrical conductivity $\left(\sim 32.7 \mathrm{MS} \mathrm{m}^{-1}\right)$ and microhardness ( 200 MPa) values are observed. This suggests that supersaturation of Sc and $\mathrm{Zr}$ can be obtained in this alloy even at the lowest cooling rate. This is consistent with a smaller driving force for precipitation of the more dilute alloy, Alloy 2.
Based on the above results, samples that had been subjected to fast oven cooling $\left(8^{\circ} \mathrm{C} / \mathrm{min}\right)$ were selected for a subsequent two-step aging treatment $\left(300^{\circ} \mathrm{C}\right.$ for $4 \mathrm{~h}$ and $425^{\circ} \mathrm{C}$ for $\left.8 \mathrm{~h}\right)$. The heating rate was $5^{\circ} \mathrm{C} / \mathrm{min}$ and the cooling rate commenced at $3^{\circ} \mathrm{C} / \mathrm{min}$ (close to the original slow oven-cooling rate). The temperature profile of the two-step aging is plotted in Fig. 3 and the slow ramp-up and cooldown rates are required to insure that no damage to the ceramic armor would occur, as noted. From our prior research, the two-step aging is the optimized treatment for these alloys to reach their maximum strength by forming precipitates with a core/shell structure, where the core is enriched in Sc and the shell is enriched in $\mathrm{Zr} .{ }^{9}$ As Sc atoms have a higher diffusivity than $\mathrm{Zr}$ atoms, after the first aging step $\left(300^{\circ} \mathrm{C}\right.$ for $\left.4 \mathrm{~h}\right)$, Sc-rich $\mathrm{Al}_{3}(\mathrm{Sc}, \mathrm{Zr})$ precipitates are nucleated while $\mathrm{Zr}$ atoms, which are much less mobile than Sc atoms, remain in the $\alpha$-Al matrix. After the second aging step $\left(425^{\circ} \mathrm{C}\right.$ for $8 \mathrm{~h}$ ), $\mathrm{Zr}$ atoms diffuse and precipitate at the surface of the Sc-rich $\mathrm{Al}_{3}(\mathrm{Sc}, \mathrm{Zr})$ precipitates and in the $\alpha$-Al matrix, forming a $\mathrm{Zr}$-enriched $\mathrm{Al}_{3}(\mathrm{Zr}, \mathrm{Sc})$ shell. ${ }^{10-12}$ The microhardness of the alloy, in the as-cast and cooled $\left(8^{\circ} \mathrm{C} / \mathrm{min}\right)$ condition and after the additional twostep aging treatment, is displayed in Fig. 4. The microhardness of both alloys in the as-cast state is about $200 \mathrm{MPa}$, which is the same as that of pure $\mathrm{Al}$, indicating that the alloys are fully supersaturated and free of precipitates. The microhardnesses of Alloys 1 and 2, after aging, reached $\sim 600 \mathrm{MPa}$ and $\sim 400 \mathrm{MPa}$, respectively, as anticipated from the formation of the strengthening $\mathrm{Al}_{3}(\mathrm{Sc}, \mathrm{Zr})$ nanoprecipitates. These strengths are about the maximum values that can be achieved by precipitation strengthening, after a classical treatment consisting of homogenization and double-aging, interspersed with water-quenching., ${ }^{9,12}$ Thus, the results demonstrate that the alloy is insensitive to the slow cooling rates (after solidification and after aging) and heating rates (before aging) and to the lack of homogenization, as anticipated from the known small diffusivities of $\mathrm{Sc}$ and $\mathrm{Zr}$ in $\mathrm{Al}$. The same

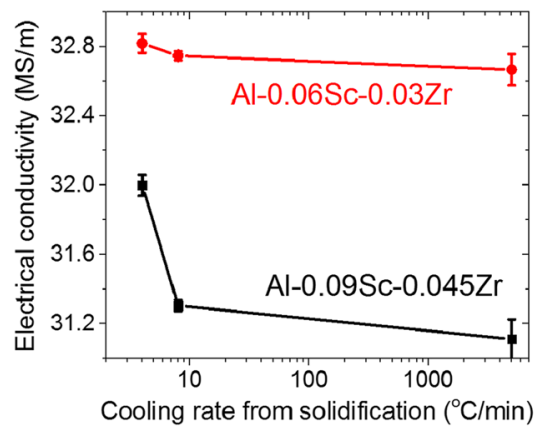

(a)

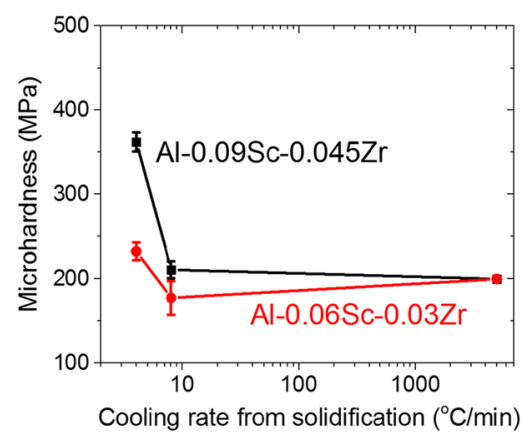

(b)

Fig. 2. (a) Electrical conductivity of Alloys 1 and 2 after cooling from $660^{\circ} \mathrm{C}$ to room temperature at different cooling rates and (b) microhardnesses of Alloys 1 and 2 after cooling from $660^{\circ} \mathrm{C}$ to room temperature at different cooling rates. 


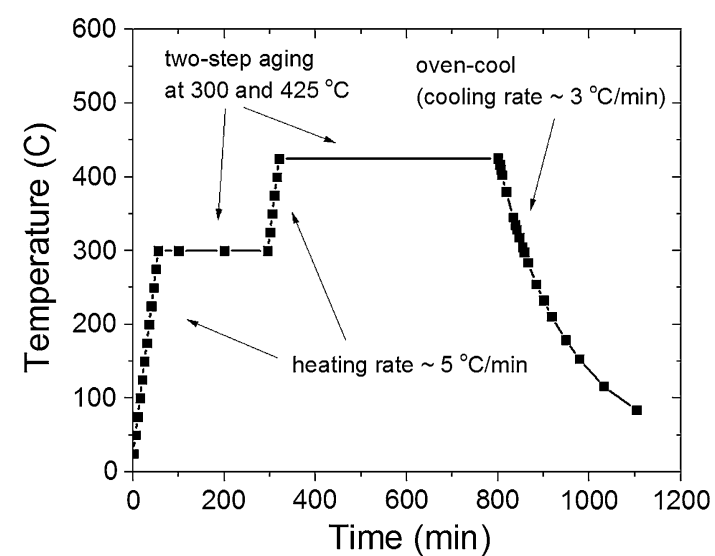

Fig. 3. Temperature versus time during the two-step heat-treatment. The heating rate is $5^{\circ} \mathrm{C} / \mathrm{min}$ and cooling rate starts at $3^{\circ} \mathrm{C} / \mathrm{min}$. Slow heating and cooling rates ensure that there is no damage to the MMC-encapsulated ceramic plates due to mismatch in the coefficients of thermal expansion between Al-MMC and the ceramic.

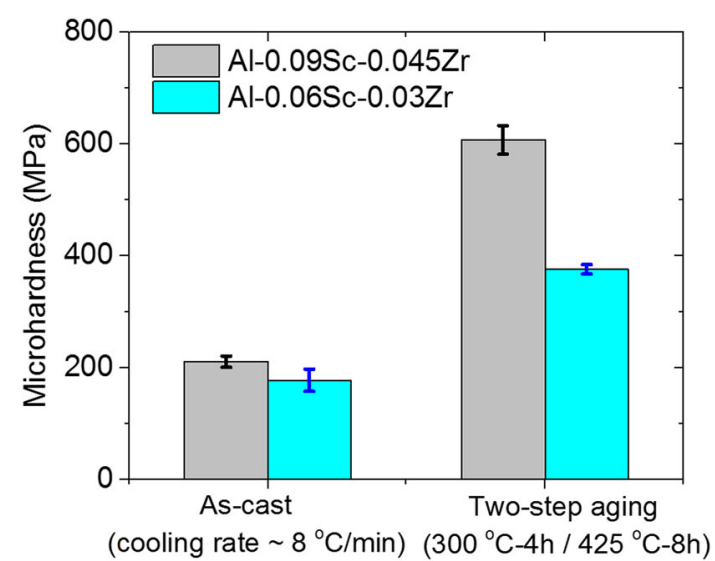

Fig. 4. Microhardness of Alloys 1 and 2 in the as-cast state (with a cooling rate from solidification of $8^{\circ} \mathrm{C} / \mathrm{min}$ ) and after a two-step aging treatment $\left(300^{\circ} \mathrm{C}\right.$ for $4 \mathrm{~h}$ and $425^{\circ} \mathrm{C}$ for $\left.8 \mathrm{~h}\right)$.

aging treatment was utilized to heat-treat the Al-Sc$\mathrm{Zr} /$ Saffil composite, presented in subsequent sections.

\section{Aluminum Metal Matrix Composite}

Based on the above results, the Al-0.09 Sc-0.045 $\mathrm{Zr}$ alloy with the highest solute content (Alloy 1) was selected for use as the metal matrix in the $\mathrm{Al}-$ Sc-Zr/Saffil composite fabrication. The Al-MMCs were cast via pressure infiltration with three Saffil short-fiber volume fractions: (1) 0\% (serving as the control sample), (2) $4 \%$ and (3) 15 vol.\%. Optical micrographs of cross-sections of the as-cast samples are displayed in Fig. 5a-c. The casting quality of the 4\% Al-MMC appears excellent with negligibly observable cavities, whereas the $15 \%$ Al-MMC exhibits micron-sized casting cavities at the fiber/matrix interfaces. The two Al-MMC samples were then aged with the same two-step aging treatment described in "Aging Treatment Optimization for the Aluminum Matrix" section. Optical micrographs of cross-sections of the aged Al-MMC samples are displayed in Fig. 5d-f and appear unchanged when compared to Fig. $4 \mathrm{~d}-\mathrm{f}$.

Microhardness and tensile results are listed in Table II. For the control unreinforced alloy, microhardness in the as-cast state, $260 \mathrm{MPa}$, is similar to that of pure $\mathrm{Al}$ matrix, suggesting that a fully supersaturated solid solution of Sc and $\mathrm{Zr}$ solutes were obtained. The microhardness in the aged state, $653 \mathrm{MPa}$, is about the maximum strength obtainable for an Al-0.09 Sc-0.045 Zr alloy by the formation of strengthening $\mathrm{Al}_{3}(\mathrm{Sc}, \mathrm{Zr})$ nano-precipitation. ${ }^{9,12}$ This strength is higher than that achieved via traditional gravity casting, $600 \mathrm{MPa}$, "Aging Treatment Optimization for the Aluminum Matrix" section. This difference may be due to a higher cooling rate from solidification during infiltration casting, which results in a more fully supersaturated solid solution, thus obtaining a higher volume fraction of strengthening $\mathrm{Al}_{3}(\mathrm{Sc}, \mathrm{Zr})$ nano-precipitates, compared to traditional gravity casting. In conclusion, the Al-0.09 Sc$0.045 \mathrm{Zr}$ alloy, Alloy 1 , appears fully compatible with the infiltration casting process in terms of casting temperature and cooling rate from solidification.

For the 4 vol.\% MMC, the microhardness in the ascast state, $362 \mathrm{MPa}$, exhibits a $100-\mathrm{MPa}$ increase as compared to the unreinforced alloy, due to the presence of the Saffil short fibers. The microhardness in the aged state, $711 \mathrm{MPa}$, is much higher than in the as-cast state, indicative of $\mathrm{Al}_{3}(\mathrm{Sc}, \mathrm{Zr})$ nano-precipitation. For the 15 vol.\% MMC, microhardness in the as-cast state, $798 \mathrm{MPa}$, already displays a large strength enhancement. The microhardness measurements of the $\alpha$-Al matrix for the 15 vol.\% sample in the as-cast state, were performed in fiber-free regions of the sample. These fiber-free regions have an elliptical morphology with a longest diameter of $\sim 300 \mu \mathrm{m}$ and a shortest diameter of $\sim 100 \mu \mathrm{m}$. These regions are probably formed due to the infiltrated liquid aluminum pushing the short fibers locally, either during infiltration or solidification. The microhardness of these fiber-free regions is, on average, $\sim 445 \mathrm{MPa}$, suggesting that $\mathrm{Al}_{3}(\mathrm{Sc}, \mathrm{Zr})$ precipitation occurs during cooling from solidification, unlike the unreinforced Al-Sc-Zr alloy and the $\mathrm{Al}-\mathrm{Sc}-\mathrm{Zr} / 4$ vol.\% Saffil composite in the as-cast state. The microhardness of the 15 vol.\% sample in the aged state, $830 \mathrm{MPa}$, shows only a slight increase in strength from the as-cast state. This further supports the indication that $\mathrm{Al}_{3}(\mathrm{Sc}, \mathrm{Zr})$ nano-precipitates are formed during casting in this sample.

Tensile stress-strain curves of the composite samples in the aged state are displayed in Fig. 6. For the control unreinforced Al-Sc-Zr alloy, the YS and UTS values are 128 and $164 \mathrm{MPa}$, respectively, with an excellent average ductility of $\sim 31 \%$ (Table II). The high ductility is anticipated from prior research. ${ }^{13}$ For the 4 vol.\% MMC, the YS and UTS values are 127 and $196 \mathrm{MPa}$, respectively, with a 


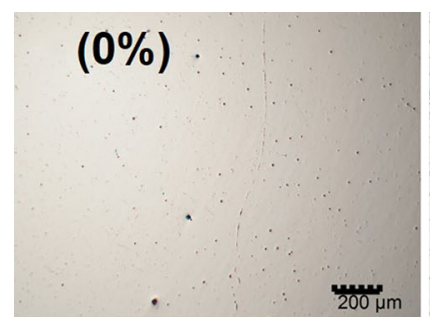

(a)

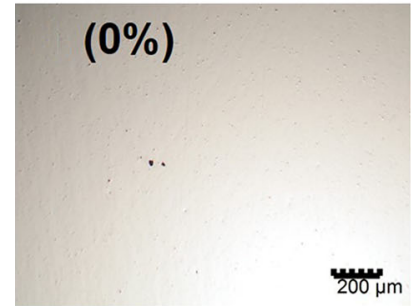

(d)

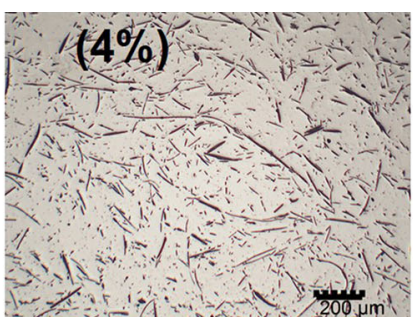

(b)

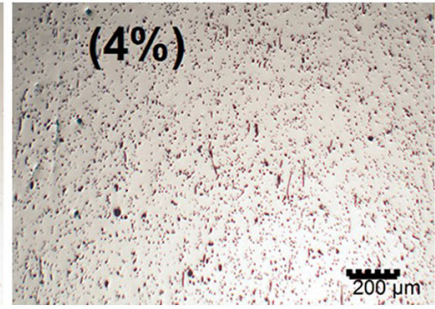

(e)

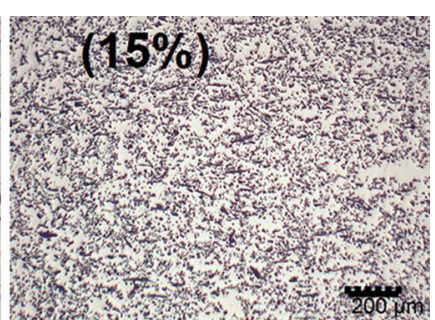

(c)

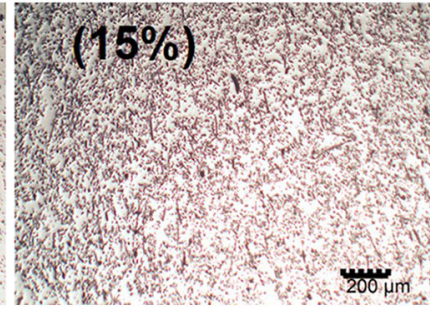

(f)

Fig. 5. Optical micrographs of cross-sections of Al-0.09 Sc- $0.045 \mathrm{Zr} /$ Saffil composites with $0 \%$ (control), $4 \%$ and $15 \%$ (vol.\%) Saffil short fibers in the as-cast state $(\mathrm{a}-\mathrm{C})$ and after a two-step aging treatment, $300^{\circ} \mathrm{C}$ for $4 \mathrm{~h}$ and $425^{\circ} \mathrm{C}$ for $8 \mathrm{~h}(\mathrm{~d}-\mathrm{f})$. The optical microstructures of the Al-MMC samples before and after aging appear qualitatively the same.

Table II. Vickers microhardnesses and tensile properties of the Al-0.09 Sc-0.045 Zr/Saffil MMC before and after aging

\begin{tabular}{|c|c|c|c|c|}
\hline \multirow[b]{2}{*}{$\begin{array}{l}\text { Saffil volume } \\
\text { fraction (vol.\%) }\end{array}$} & \multirow[b]{2}{*}{ Microhardness (MPa) } & \multicolumn{3}{|c|}{ Tensile properties } \\
\hline & & $\begin{array}{c}\text { Yield } \\
\text { strength } \\
\text { (MPa) } \\
\end{array}$ & $\begin{array}{l}\text { Ultimate tensile } \\
\text { strength (MPa) } \\
\end{array}$ & $\begin{array}{c}\text { Elongation } \\
(\%) \\
\end{array}$ \\
\hline 0 (as-cast) & $260 \pm 9$ & - & - & - \\
\hline 0 (aged) & $653 \pm 24$ & $128 \pm 3$ & $164 \pm 7$ & $31 \pm 2$ \\
\hline 4 (as-cast) & $362 \pm 23$ & - & - & - \\
\hline 4 (aged) & $711 \pm 49$ & $127 \pm 7$ & $196 \pm 1$ & $10 \pm 0.5$ \\
\hline 15 (as-cast) & $798 \pm 45\left(\sim 445 \pm 23^{\mathrm{a}}\right)$ & - & - & - \\
\hline 15 (aged) & $830 \pm 68$ & $135 \pm 6$ & $>150$ & $0.4 \pm 0.1$ \\
\hline
\end{tabular}

${ }^{\mathrm{a}}$ In fiber-free matrix region.

reduced, but useful, average ductility of $\sim 10 \%$ (Table II). Thus, with an addition of about 4 vol.\% Saffil short-fibers, the same YS and an increase of $32 \mathrm{MPa}(\sim 20 \%)$ in UTS are obtained, compared to the control alloy, while the ductility drops by a factorof $\sim 3$ from $31 \%$ to $10 \%$. The 15 vol. $\%$ MMC samples fractured at a very low elongation, $0.4 \%$. The lack of tensile ductility in this sample is likely due to the cavities present at the interfaces between Saffil fibers and the $\alpha$-Al matrix.

\section{DISCUSSION}

\section{Reactivity Between Matrix Solutes (Sc, Zr) and Saffil Short Fibers in the Melt}

A prior study ${ }^{14}$ has demonstrated that the reactivity of $\mathrm{Sc}$ and $\mathrm{Al}_{2} \mathrm{O}_{3}$ is negligible in an $\mathrm{Al}$ $0.18 \mathrm{Sc}$ wt.\% alloy containing $30 \mathrm{vol} \%$ of $\mathrm{Al}_{2} \mathrm{O}_{3}$ dispersoids created by melt infiltration. A high number density of $\mathrm{L}_{2}$-structured $\mathrm{Al}_{3} \mathrm{Sc}$ nanoscale precipitates was formed after heat treating, coexisting with the alumina dispersoids. These $\mathrm{Al}_{3} \mathrm{Sc}$ nano-precipitates enhanced both ambient strength and creep resistance at elevated temperatures of the studied composite. ${ }^{14}$ The present Al-Sc-Zr/4 vol.\% Saffil composite displays a large microhardness enhancement from the as-cast to the aged state $(\Delta \mathrm{HV} \approx 350 \mathrm{MPa})$, which is consistent with precipitation strengthening via formation of $\mathrm{Al}_{3}(\mathrm{Sc}, \mathrm{Zr})$ nano-precipitates. Thus, this suggests that small concentrations of $\mathrm{Sc}$ and $\mathrm{Zr}$ in an aluminum melt do not significantly react with Saffil short fibers and that these elements remain supersaturated in the Al-matrix in the as-cast state. Additionally, an SEM-EDS elemental map ( $\times 6000$ magnification) does not reveal $\mathrm{Sc}$ and $\mathrm{Zr}$ enrichment around the 


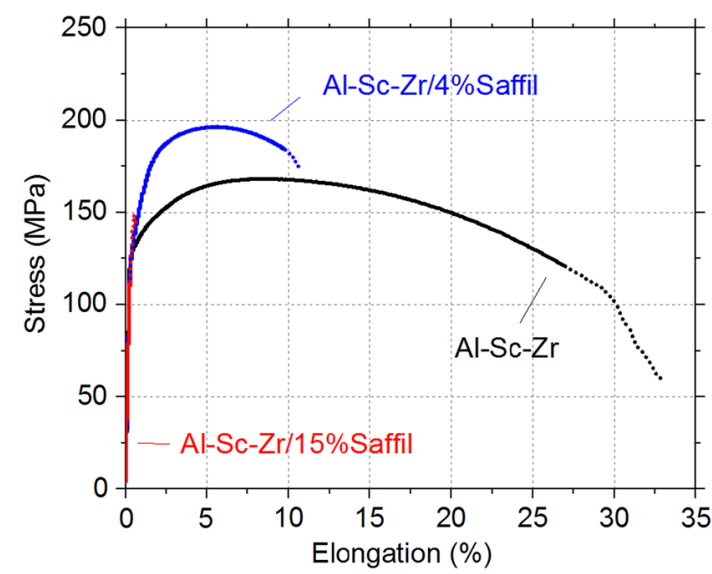

Fig. 6. Engineering stress versus strain curves of the Al-0.09 Sc$0.045 \mathrm{Zr} /$ Saffil composite samples with two Saffil volume fractions (and the unreinforced matrix), after a two-step aging treatment, $300^{\circ} \mathrm{C}$ for $4 \mathrm{~h}$ and $425^{\circ} \mathrm{C}$ for $8 \mathrm{~h}$. The dotted line indicates the elongation's deviation from testing different samples.

Saffil short fibers, further supporting the argument that dilute concentrations of $\mathrm{Sc}$ and $\mathrm{Zr}$ solutes do not react with the fibers in the melt.

\section{Non-quenching Ability of Al-Sc-Zr Alloys}

As previously discussed, the ability to cool slowly from solidification to ambient temperature without solute precipitation (i.e., non-quenching ability) is one of the most crucial requirements for fabricating hybrid composite materials with Al-alloys or AlMMC-encapsulating ceramic materials. The slow cooling process during solidification is required to minimize, via creep relaxation, the buildup of internal stresses from CTE mismatches between the matrix and ceramic material. Al-Sc-Zr-based alloys are particularly suitable for this non-quenching requirement, as the diffusivities of $\mathrm{Sc}$ and especially $\mathrm{Zr}$ are small in solid aluminum. The diffusion activation energies of $\mathrm{Sc}$ and $\mathrm{Zr}$ in $\alpha-\mathrm{Al}$ are $1.79 \mathrm{eV} /$ atom and $2.51 \mathrm{eV} /$ atom,${ }^{15-17}$ respectively. For comparison, the value for $\mathrm{Cu}$ is $1.40 \mathrm{eV} /$ atom. ${ }^{17}$ The temperature-time transformation (TTT) diagrams of dilute Al-Sc and Al-Sc-Zr alloys were extensively investigated. ${ }^{13}$ These demonstrate that, with a small addition of $\mathrm{Zr}(0.15$ wt.\%) to $\mathrm{Al}-0.4 \mathrm{Sc}$ wt.\% alloy, the precipitation of the $\mathrm{Al}_{3}(\mathrm{Sc}, \mathrm{Zr})$ phase is drastically delayed due to the sluggish diffusivity of $\mathrm{Zr}$ atoms. This behavior was also demonstrated in many prior studies. ${ }^{10,11,18,19}$ As described above, a completely supersaturated solid solution can be obtained in Alloy 1 (Al-0.15 Sc-0.15 Zr wt.\%) with a cooling rate as small as $8^{\circ} \mathrm{C} / \mathrm{min}$. This value is in line with the TTT diagram of the Al-0.4 Sc-0.15 Zr wt.\% alloy. ${ }^{13}$ In the largest castings of the hybrid plates ( $\sim 10 \mathrm{~cm}$ thickness and $\sim 1 \mathrm{~m}$ in length and width), the cooling rate from solidification in the center of the plate is the smallest. Thus, the nonquenching ability is also important for maintaining a fully supersaturated solid solution at the center of the plates. Additionally, when the hybrid modules contain a large amount of an insulating ceramic material, tolerance for heat treatments with slow heating and cooling rates is required to reduce hot cracking and warping susceptibility.

\section{Strengthening Mechanism of Nanoscale $\mathbf{A l}_{3}$ (Sc,Zr) Precipitates}

Precipitation kinetics and strengthening mechanisms of $\mathrm{Al}_{3}(\mathrm{Sc}, \mathrm{Zr})$ nanoscale precipitates have been investigated extensively in prior studies. ${ }^{10,11,18,20,21}$ The two-step aging treatment utilized in the present study is anticipated to form core/shell structured precipitates in our Al-0.09 Sc-0.045 Zr alloy, where the cores are enriched in Sc and the shells are enriched in $\mathrm{Zr}$ atoms because $\mathrm{Sc}$ has a higher diffusivity than $\mathrm{Zr}$ atoms. ${ }^{10,11,18}$ Due to the sluggish diffusivity of $\mathrm{Zr}$, this Zr-enriched shell also acts as a diffusion barrier, resulting in outstanding thermal stability of the $\mathrm{Al}_{3}(\mathrm{Sc}, \mathrm{Zr})$ core-shell precipitates extending to $400^{\circ} \mathrm{C}$ for at least 64 days. ${ }^{9,20}$ Based on the measured microhardness increase from the ascast to the aged state $(\Delta \mathrm{HV}=400 \mathrm{MPa})$, corresponding to a YS increase of $\sim 130 \mathrm{MPa}$ $(\Delta \mathrm{YS} \sim \Delta \mathrm{HV} / 3)$, the mean radius of the $\mathrm{Al}_{3}(\mathrm{Sc}, \mathrm{Zr})$ nano-precipitates in our Al-0.09 Sc-0.045 $\mathrm{Zr}$ alloy, Alloy 1 , is estimated to be $3-5 \mathrm{~nm} .^{9,12}$ The main precipitation strengthening mechanism is then anticipated to be an admixture of order strengthening and Orowan dislocation looping. ${ }^{22,23}$ Detailed discussions of the precipitation strengthening of this alloy can be found elsewhere. ${ }^{22}$ It should be noted that grain boundary strengthening is negligible in all studied composite samples. The measured average grain size of the control Al-Sc-Zr alloy, Al-Sc-Zr/4\% vol.\% Saffil and Al-Sc-Zr/15\% vol.\% Saffil composite is about 2,1 , and $0.3 \mathrm{~mm}$, respectively.

In the Al-Sc-Zr/15 vol.\% Saffil composite sample, the high measured microhardness of $798 \mathrm{MPa}$ (Table II) in the as-cast state, indicates that the strengthening $\mathrm{Al}_{3}(\mathrm{Sc}, \mathrm{Zr})$ nano-precipitates are already formed in the as-cast state. This is surprising, as the precipitation of $\mathrm{Al}_{3}(\mathrm{Sc}, \mathrm{Zr})$ nano-precipitates were not observed in the control Al-Sc-Zr alloy nor in the Al-Sc-Zr/4\% vol.\% Saffil composite. Saffil short-fibers consist of at least $96 \mathrm{vol} . \% \mathrm{Al}_{2} \mathrm{O}_{3}$ with a small concentration of $\mathrm{SiO}_{2}(<4$ vol. $\%){ }^{24}$ In the SEM-EDS elemental map, a signal from $\mathrm{Si}$ was actually detected around all $\mathrm{Al}_{2} \mathrm{O}_{3}$ short-fibers. Prior studies show that $\mathrm{SiO}_{2}$ can react with liquid aluminum to form $\mathrm{Al}_{2} \mathrm{O}_{3}$ and $\mathrm{Si}^{25}$ Depending on their concentrations, the $\mathrm{Si}$ atoms form $\mathrm{Si}$ precipitates or remain dissolved in the $\alpha-\mathrm{Al}$ matrix. ${ }^{25}$ It is unclear if the Si signal observed in the SEM-EDS study came from $\mathrm{SiO}_{2}$, Si precipitates or $\mathrm{Si}$ atoms. The likely existence of $\mathrm{Si}$ atoms in the liquid aluminum, leached from the Saffil fibers during the time the Al-Sc-Zr matrix of the 15 vol.\% Saffil composite is liquid, may explain the unexpected 
formation of $\mathrm{Al}_{3}(\mathrm{Sc}, \mathrm{Zr})$ nano-precipitates during slow cooling after solidification. In prior work, ${ }^{20,26,27}$ the precipitation kinetics of Sc and $\mathrm{Zr}$ were shown to be strongly accelerated by the addition of small concentrations of Si. For example, Si at the impurity level (0.025 at.\%) increases the nucleation current of $\mathrm{Al}_{3} \mathrm{Sc}$ in dilute $\mathrm{Al}-\mathrm{Sc}$ alloys, with the Sc concentration in the range $0.025-0.065$ at. $\%{ }^{28}$ Silicon was also found to precipitate with $\mathrm{Sc}$ to form $(\mathrm{Al}, \mathrm{Si})_{3} \mathrm{Sc}$ precipitates in an Al-0.16 Sc-0.05 Si wt.\% alloy. ${ }^{29} \mathrm{~A}$ dilute $\mathrm{Al}-0.06 \mathrm{Sc}-0.06 \mathrm{Zr}$ at.\% alloy with 0.06 at.\% $\mathrm{Si}$ also exhibited faster precipitate nucleation and growth, as compared to an alloy without $\mathrm{Si}^{26}$ It was hypothesized that Si binds with Sc and/or $\mathrm{Zr}$ atoms, where the Si-Sc and Si-Zr dimers have faster diffusivities in the $\alpha$-Al matrix when compared to the individual $\mathrm{Sc}$ and $\mathrm{Zr}$ atoms, respectively. ${ }^{26}$ Finally, a recent systematic study of the effect of $\mathrm{Si}$, with concentrations in the range $0-0.2$ at.\% in the dilute $\mathrm{Al}-0.55 \mathrm{Sc}-0.02 \mathrm{Zr}-0.005 \mathrm{Er}$ at.\% demonstrated that the higher the Si concentration, the faster the precipitation kinetics of $(\mathrm{Al}, \mathrm{Si})_{3}(\mathrm{Sc}, \mathrm{Zr}, \mathrm{Er})$ nano-precipitates, resulting in shorter aging times to achieve the peak strength. ${ }^{27}$

\section{Strengthening Mechanism of Saffil Short Fi- bers}

The volume fractions of Saffil short fibers in the two MMCs studied here, 4 and 15 vol.\%, are relatively small, and thus the strengthening effects from these fibers are anticipated to be modest. The yield strengths of the two MMCs are about the same as in the control alloy in the aged state (Table II). This demonstrates that the onset of plastic deformation occurs in the metal matrix with relatively modest load transfer to the randomly oriented short fibers. The UTS of the $4 \mathrm{vol} \%$ composite is higher than in the control alloy in the aged state, Table II, suggesting that the short fibers partially constrain matrix flow and/or are subjected to load transfer, resulting in a higher strain hardening and a higher UTS (Fig. 6). Additionally, the microhardness is increased from $653 \mathrm{MPa}$ in the control alloy to $711 \mathrm{MPa}$ (9\% increase) in the 4 vol.\% MMC and to $830 \mathrm{MPa}(27 \%$ increase $)$ in the 15 vol.\% MMC (Table II).

The average ductility decreases from $31 \%$ in the control alloy to $10 \%$ in the 4 vol. $\%$ MMC and $0.4 \%$ in the 15 vol.\% MMC. This drastic effect on ductility is present in all Al-MMCs.,30,31 Due to the elastoplastic mismatch between the $\mathrm{Al}$ matrix and the fibers, high stress concentrations are developed around the fibers during the deformation of the matrix, leading to crack initiation and propagation at the fiber/matrix interface and reduction of ductility in the composite, as compared to the metal matrix. In the 15 vol.\% MMC, cavities at the fiber/matrix interface already pre-exist in the ascast state, which can easily nucleate cracks at a relatively small applied stress and cause premature failure, as observed in this study.

\section{Strength and Toughness}

Figure 7 shows stress-strain curves of the present $\mathrm{Al}-0.09 \mathrm{Sc}-0.045 \mathrm{Zr} / 4$ vol.\% Saffil composite as compared to $\mathrm{Al}-2 \mathrm{Cu} / \mathrm{Saffil}$ composite samples from the literature with different Saffil volume fractions ranging from 0 vol.\% to 40 vol.\% commercialized by CPS Technologies. ${ }^{1}$ The $\mathrm{Al}-2 \mathrm{Cu}$ wt.\% matrix is commonly used to fabricate Al-MMC with Saffil fibers because $\mathrm{Cu}$ does not react with alumina and primary intermetallic phases do not form in the matrix. ${ }^{2}$ The alloy's low yield strength also allows global load sharing and thus composite strength is a function of the Weibull strength of the fiber. If the yield strength is higher, it reaches a point where individual fibers break and transfer their load to adjacent fibers in such a way that the composite strength is no longer a function of the fiber Weibull strength but is rather a function of the strength of the weakest fibers in the composite. ${ }^{2}$ Table III lists the UTS and minimum elongation values of all tested samples (see footnote 1). As anticipated, higher Saffil volume fractions result in higher

Table III. Minimum toughness, UTS and minimum elongation of Al-2Cu/Saffil composite samples with different Saffil short fiber volume fractions ranging from 0 vol. $\%$ to 40 vol. $\%$

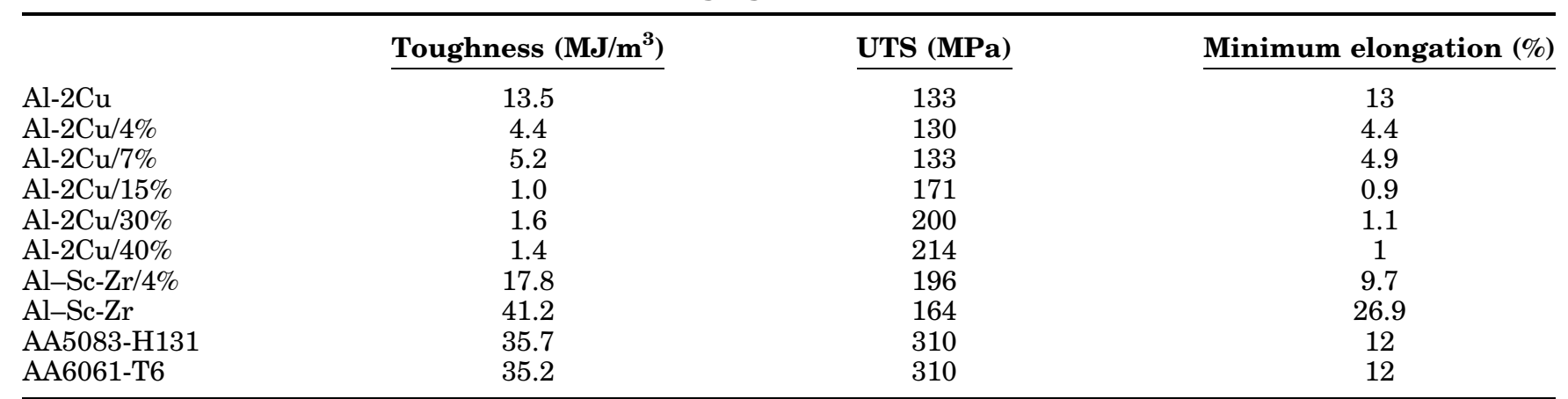

The Al-2Cu/Saffil data were provided by CPS Technologies. Values for Al-0.09 Sc-0.045 Zr and Al-0.09 Sc-0.045 Zr/4 vol.\% Saffil from the present study are also included. 


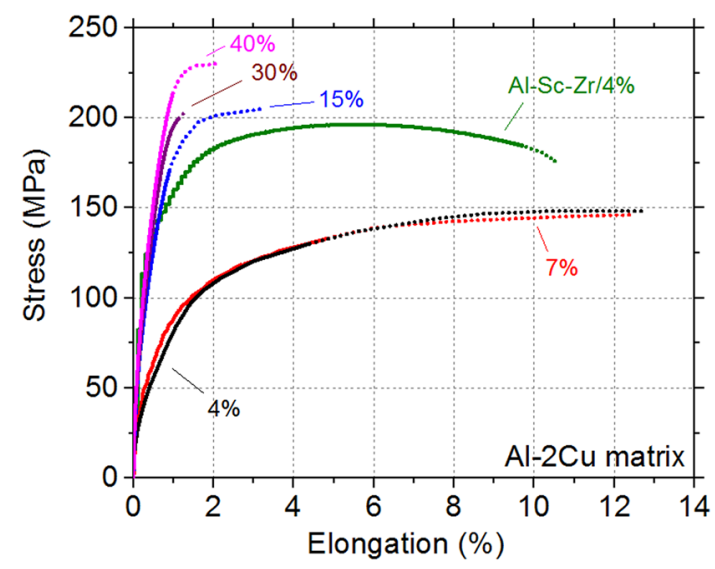

Fig. 7. Stress versus strain curve of the Al-0.09 Sc-0.045 Zr/ $4 \%$ Saffil composite (Alloy 1), compared to the Al-2Cu/Saffil composite samples with different Saffil volume fractions. The dotted line indicates the elongation deviation from testing different samples. Data for $\mathrm{Al}-2 \mathrm{Cu} / \mathrm{Saffil}$ composite samples are provided by CPS Technologies.

UTS and smaller minimum elongation values in the $\mathrm{Al}-2 \mathrm{Cu} / \mathrm{Saffil}$ composite. The toughness is also calculated, i.e., the area under the stress-strain curve, for all samples and is listed in Table III. The Al$2 \mathrm{Cu} /$ Saffil composite with 7 vol.\% Saffil exhibits the best toughness, $5.2 \mathrm{MJ} / \mathrm{m}^{3}$. For the Al-Sc-Zr alloy and Al-Sc-Zr/4 vol.\% Saffil composites, the measured toughness values are 41.2 and $17.8 \mathrm{MJ} / \mathrm{m}^{3}$, respectively, which is about $8-3$ times higher than the best performing $\mathrm{Al}-2 \mathrm{Cu} / \mathrm{Saffil}$ composite. These results are promising for $\mathrm{Al}-\mathrm{Sc}-\mathrm{Zr}$ alloy and $\mathrm{Al}-\mathrm{Sc}$ $\mathrm{Zr} / 4$ vol.\% Saffil composite application to hybrid materials systems, as well as any other application that requires medium-strength and high-toughness characteristics, while providing the anticipated enhanced stiffness, abrasion resistance and creep resistance from fiber reinforcement.

Good candidates for ballistic and blast protection material, aluminum alloys and Al-MMCs are required to have (1) high strength, (2) good ductility, (3) high corrosion resistance, (4) good weldability and (5) especially high toughness. Thus, one of the most common $\mathrm{Al}$ alloys utilized in armor application, AA5083-H131, shows an UTS of $310 \mathrm{MPa}$, an elongation of $12 \%$ and a toughness of $35.7 \mathrm{MJ} \mathrm{m}^{-3}$ (Table III). An alternative to this alloy is AA6061T6, having about the same values in UTS, elongation and toughness. Both these alloys have excellent corrosion resistance, especially AA5083-H131, and good weldability. The latter alloy is widely utilized in armor and many other applications. The present Al-0.09 Sc-0.045 Zr alloy reaches, after the two-step aging treatment, a relatively low UTS of $164 \mathrm{MPa}$, an excellent minimum elongation of $27 \%$ and a minimum toughness of $41.2 \mathrm{MJ} \mathrm{m}^{-3}$. It has a smaller strength but a higher toughness than the alloys AA5083-H131 and AA6061-T6. Their excellent ductility is due to the fact that the dilute Al-Sc$\mathrm{Zr}$ alloy has a high purity, $99.7 \mathrm{wt} \% \mathrm{Al}$, and contains only coherent $\mathrm{L}_{2}$-structured $\mathrm{Al}_{3}(\mathrm{Sc}, \mathrm{Zr})$ nano-precipitates as the strengthening phase, as opposed to second-phase particles that are incoherent, micron-size and at grain boundaries. The Al-Sc$\mathrm{Zr}$ alloy is anticipated to have excellent corrosion resistance due to, again, its high purity. It should also have excellent weldability due to the highly thermally stable nano-precipitates that do not rapidly coarsen at elevated temperatures. Prior studies $^{32-36}$ show that Al-Sc-based alloys have excellent weldability, specifically friction-stir welding. Thus the combination of excellent ductility, toughness, corrosion resistance and weldability makes the present Al-Sc-Zr alloy attractive for armor application. For this application, future work is, however, required to improve further the yield strength further, while maintaining the high ductility.

The Al-Sc-Zr/4 vol.\% Saffil composite has a higher UTS, $196 \mathrm{MPa}$, but a lower minimum ductility, $9.7 \%$, and toughness, $17.8 \mathrm{MJ} . \mathrm{m}^{-3}$, compared to the unreinforced Al-0.09 Sc-0.045 Zr alloy. Its toughness is also lower than the baseline armor alloys AA5083-H131 and AA6061-T6. It is, however, a good encapsulating material for the above-mentioned hybrid armor system, as the preformed Saffil short fibers function as a mold or fixturing to structurally hold the ceramic tiles in place during the infiltration casting. Thus, the composite matrix shows an advantage in the fabrication process.

\section{CONCLUSION}

In this article, we presented a newly developed $\mathrm{Al}$ alloy with dilute concentrations of $\mathrm{Sc}$ and $\mathrm{Zr}$, useable with or without a low volume fraction of Saffil short alumina fiber reinforcement for hybrid material system applications. We reach the following conclusions:

(a) Dilute Al-0.06 Sc-0.03 Zr and Al-0.09 Sc-0.045 $\mathrm{Zr}($ at.\%) alloys achieve a nearly fully supersaturated solid solution when gravity-cast, solidified and cooled to ambient temperature at a cooling rate as small as $8^{\circ} \mathrm{C} / \mathrm{min}$. A subsequent two-step aging treatment, $300^{\circ} \mathrm{C}$ for $4 \mathrm{~h}$ and $425^{\circ} \mathrm{C}$ for $8 \mathrm{~h}$, with slow heating and cooling rates, was utilized to precipitate these elements to form $\mathrm{L1}_{2}$-structured $\mathrm{Al}_{3}(\mathrm{Sc}, \mathrm{Zr})$ nano-precipitates with high strengthening potency.

(b) The pressure infiltrated Al-0.09 Sc-0.045 Zr at.\% alloy achieves a nearly fully supersaturated solid solution of $\mathrm{Sc}$ and $\mathrm{Zr}$ in the as-cast state and exhibits the same strength, due to $\mathrm{Al}_{3}(\mathrm{Sc}, \mathrm{Zr})$ precipitation, in the aged state as is observed in the traditional gravity cast alloys.

(c) The Al-0.09 Sc-0.045 Zr at.\% alloy, pressure infiltrated into a $15 \%$ Saffil fiber composite, exhibits high strength in the as-cast state, indicating that the strengthening $\mathrm{Al}_{3}(\mathrm{Sc}, \mathrm{Zr})$ precipitates are already formed during cooling from solidification. Silicon impurities, gener- 
ated from a reaction between silica and molten aluminum, are a possible cause for the accelerated precipitation kinetics of $\mathrm{Al}_{3}(\mathrm{Sc}, \mathrm{Zr})$ precipitates.

(d) The pressure infiltrated Al-0.09 Sc-0.045 Zr at.\% alloy, after a two-step aging treatment, reached a moderate UTS of $164 \mathrm{MPa}$ and a high ductility of $31 \%$, resulting in an excellent toughness of $41 \mathrm{MJ} \mathrm{m}^{-3}$. The corresponding $4 \%$ Saffil composite, after a similar two-step aging treatment, reached a somewhat higher UTS of $196 \mathrm{MPa}$ and a much smaller, but still useful, ductility of $10 \%$ and a toughness of $18 \mathrm{MJ} \mathrm{m}^{-3}$. The $15 \%$ Saffil composite, after a similar two-step aging treatment, displays premature failure during tensile testing. This is most likely due to casting defects at the fiber/matrix interfaces.

(e) The toughness of the pressure infiltrated Al$0.09 \mathrm{Sc}-0.045 \mathrm{Zr}$ at.\% alloy, after aging, is higher than that in the baseline armor alloys, AA5083-H131 and AA6061-T6. The new alloy's combination of moderate strength and excellent ductility, toughness, corrosion resistance, weldability non-quench ability gives it great potential as part of a hybridized armor system, in unreinforced form or as a matrix of a composite.

\section{ACKNOWLEDGEMENTS}

This research was sponsored, in part, by Army Research Laboratory and was accomplished under Cooperative Agreement Number W911NF-10-20098 (V.K. Champagne, monitor). The views and conclusions contained in this document are those of the authors and should not be interpreted as representing the official policies, either expressed or implied, or the Army Research Laboratory or the U.S. Government. The U.S. Government is authorized to reproduce and distribute reprints for Government purposes notwithstanding any copyright notation herein. The authors also gratefully acknowledge CPS Technologies Inc. for fabricating the composite samples. The authors kindly thank M. Burkins (ARL) and B. McWilliams (ARL) for reviewing the manuscript and providing valuable comments. Useful discussions with Prof. D. Luzzi (Northeastern University) are acknowledged.

\section{REFERENCES}

1. http://www.alSaffil.com/pdf/CPS_Lightweight_Structural_ Composites_REV_032212.pdf. Accessed 1 Dec 2015.

2. C. McCullough, P. Galuska, and S.R. Pittman, Design Fundamentals of High Temperature Composites, Intermetallics, and Metal-Ceramics System, ed. R.Y. Lin, Y.A. Chang, G. Reddy, and C.T. Liu (Warrendale: TMS, 1996), p. 15.
3. ASM Handbook, Properties and Selection: Non Ferrous Alloys, Vol. 2 (Materials Park: ASM International, 1990).

4. A. Mortensen and J. Llorca, Annu. Rev. Mater. Res. 40, 243 (2010).

5. A.R. Bunsell, Handbook of Ceramic Composites, ed. N.P. Bansal (Boston: Kluwer Academic Publishers, 2005), p. 10.

6. ALCOA, U.S. Patent 3,547,180 (15 Dec 1970). http://www. google.com/patents/US3547180.

7. M.E. van Dalen, D.C. Dunand, and D.N. Seidman, Acta Mater. 59, 5224 (2011).

8. K.E. Krug, A. Werber, D.C. Dunand, and D.N. Seidman, Acta Mater. 58, 134 (2010).

9. C. Booth-Morrison, D.C. Dunand, and D.N. Seidman, Acta Mater. 59, 7029 (2011).

10. C.B. Fuller, J.L. Murray, and D.N. Seidman, Acta Mater. 53, 5401 (2005).

11. C.B. Fuller and D.N. Seidman, Acta Mater. 53, 5415 (2005).

12. C.B. Fuller, D.N. Seidman, and D.C. Dunand, Acta Mater. 51, 4803 (2003).

13. J. Royset and N. Ryum, Int. Mater. Rev. 50, 19 (2005).

14. R.A. Karnesky, L. Meng, and D.C. Dunand, Acta Mater. 55, 1299 (2007).

15. E.A. Marquis and D.N. Seidman, Acta Mater. 49, 1909 (2001).

16. T. Marumo, S. Fujikawa, and K. Hirono, J. Jpn. Inst. Light Met. 23, 17 (1973).

17. A.D. LeClaire and G. Neumann, 3.2.13 Aluminum group metals. H. Mehrer, (ed.). Springer Materials-The LandoltBörnstein Database.

18. K.E. Knipling, R.A. Karnesky, C.P. Lee, D.C. Dunand, and D.N. Seidman, Acta Mater. 58, 5184 (2010).

19. K.E. Knipling, D.N. Seidman, and D.C. Dunand, Acta Mater. 59, 943 (2011).

20. N.Q. Vo, D.C. Dunand, and D.N. Seidman, Acta Mater. 63, 73 (2014).

21. C. Booth-Morrison, D.N. Seidman, and D.C. Dunand, Acta Mater. 60, 3643 (2012).

22. D.N. Seidman, E.A. Marquis, and D.C. Dunand, Acta Mater. 50, 4021 (2002).

23. E. Nembach, Particle Strengthening of Metals and Alloys (New York: Wiley, 1997).

24. http://www.saffil.com/index/fibre_home/property_informa tion.aspx. Accessed 1 Dec 2015.

25. P.K. Rohatgi, B.C. Pai, and S.C. Panda, J. Mater. Sci. 14, 2277 (1979).

26. C. Booth-Morrison, Z. Mao, M. Diaz, D.C. Dunand, C. Wolverton, and D.N. Seidman, Acta Mater. 60, 4740 (2012).

27. N.Q. Vo, D.C. Dunand, and D.N. Seidman, Northwestern University, Evanston, IL, unpublished research, 2014.

28. O. Beeri, D.C. Dunand, and D.N. Seidman, Mater. Sci. Eng. A 527, 3501 (2010).

29. G. Du, J. Deng, Y. Wang, D. Yan, and L. Rong, Scr. Mater. $61,532(2009)$

30. L. Weber, R. Tavangar, and A. Mortensen, Scr. Mater. 53, 17 (2005).

31. R. Tavangar, S. Nategh, and L. Weber, Mater. Sci. Technol. 20, 1645 (2004).

32. N.Q. Vo, D.C. Dunand, and D.N. Seidman, Acta Mater. 60, 7078 (2012).

33. J. Zhao, F. Jiang, H. Jian, K. Wan, L. Jiang, and X. Chen, Mater. Design 31, 306 (2010).

34. X. Sauvage, A. Dede, A.C. Munoz, and B. Huneau, Mater. Sci. Eng. A 491, 364 (2008).

35. N. Kumar, R.S. Mishra, C.S. Huskamp, and K.K. Sankaran, Scr. Mater. 64, 576 (2011).

36. N. Kumar, R.S. Mishra, C.S. Huskamp, and K.K. Sankaran, Mater. Sci. Eng. A 525, 5883 (2011). 